\title{
Modeling of Prototype System Digital Irigation
}

\author{
Mambang $1^{\text {st }}$, Finki Dona Marleny*2 $2^{\text {rd }}$ \\ \{mambang@unism.ac.id, finkidona@unism.ac.id\} \\ Information Technology, Sari Mulia University, Jl. Scout 2, PemurusAffairs. District. East Banjarmasin, \\ Banjarmasin, South Kalimantan, 70 238, Indonesia
}

\begin{abstract}
Science and technology has changed human life today, almost all industrial sectors are assisted by artificial intelligence machines, the fourth generation industrial revolution brings human life always side by side with intelligent systems, besides the industrial sector, agriculture is currently undergoing a revolution digital to be able to empower farmers, one of which is to optimize the use of irrigation as a provision and regulation of water to support agriculture. The research aims to create a microcontroller-based digital irrigation prototype that can empower farmers and provide decision support systems for farmers in the face of the water crisis on dry land. By using a controller-based system, farmers will be able to monitor and control the water supply system using a smartphone that is connected to the system and can assist farmers in making decisions for their land. By utilizing microcontrollerbased Internet of Things (IoT) technology using raspberry Pi and Arduino, where the digital irrigation prototype is run using a smartphone that sends data to a microcontroller-based server and is received by sensors that have been connected using raspberry and Arduino.
\end{abstract}

Keywords: Digital Irrigation, IoT, Smart Farming

\section{Introduction}

Science and technology have changed human life today, almost all industrial sectors are assisted by artificial intelligence, revolution fourth generation industry brings human life always side by side with the system, intelligent system, in addition to the industrial sector, agriculture is currently being renewed for the digital revolution can empower farmers, one of which is to optimize irrigation use as providing and regulating air to support agriculture. The main technology and application domain that makes it possible to encourage IoT Internet and distributed computing directed at the technology research community, Cloud centric vision for worldwide implementation of Internet of Things. The key enabling technologies and application domains that are likely to drive IoT research [1].

Development that emphasizes the use of internal information and communication technology the cycle of cyber farming management or also called smart farming utilizes new technology like the Internet of Things and Cloud Computing and introducing more robots and artificial intelligence in agriculture [2], this shows that smart farming can as a way to empower farmers who carry out traditional agricultural activities. To create a prototype microcontrollerbased digital land that can empower Farmers and provide decision support systems for deep farmers overcome the water crisis on dry land.

Required and moved using an inventory system using a smartphone connected with the system and can help farmers in making decisions for the land. By utilizing microcontrollerbased Internet of Things (IoT) technology using Raspberry Pi and Arduino, where the digital 
irrigation prototype is run using a smartphone that sends data to a microcontroller-based server and is received by sensors that have been connected using raspberry and Arduino.

Recent research hypothetically shows the potential of the Internet of Things (IoT) to transform large industries for a better world, which includes its impact on the agricultural industry. The agricultural industry must understand IoT to feed 9.6 billion global populations by 2050 [3]. The future of Smart Farming can describe two extreme scenarios: 1) closed ownership system where farmers are part of the food supply chain integrated or 2) an open collaborative system where farmers and each stakeholder Literature review is not more than 1000 words by presenting state of the art in the field researched [2].

Jayaraman's research, presented SmartFarmNet, a deep pioneering effort build a measured data acquisition, analysis and sensor visualization platform for agricultural applications smart, based on the Internet of Things. To present the platform architecture design aims to support almost all IoT devices, allowing absorption and IoT data visualization quickly using zeroprogramming efforts, and providing virtual laboratory environment for visualizing and sharing study data [4].

The Bronson article, refers to the innovation literature that is responsible for suggesting concrete process for including rights holders in the "smart" agricultural revolution. This research highlights how productivity values encourage seed innovation with consequences specifically for the distribution of power in the food system. Next, the article use document analysis to show that the same value framework is motivating public investment in smart agricultural innovation [5]. Optimizing water consumption is the main challenge for agriculture that is more sustainable by paying attention to the environment. By combining micro technology and nanotechnology with the solutions offered from IoT connections, the new sensors enable farmers to connect to their agricultural production by mastering in real time the exact contributions needed in water and fertilizer [6].

The Arduino weather monitoring station is providing correct data values for the real time clock and the temperature sensor [7]. Microcontroller-based digital irrigation prototype that can empower farmers and provide decision support systems for farmers in facing the water crisis on dry land. By using a controller-based system, farmers will be able to monitor and control water supply systems using smartphones connected to the system.

Another advantage of this research is reviewing the use of integrated systems using the Internet of Things-based Information Technology infrastructure.

\section{Proposed Prototype Architecture}

Authors propose a irrigation prototype based on equipment and technologies supported by microcontroller. The proposed system includes the following parts:

a. The microcontroller processing Arduino Uno module (ATMega328P) that controls the sensors, the actuator that is responsible for data upload to as.

b. Ethernet Shield works by providing IP services on Arduino and PC in order to connect to the internet.

c. Raspberry Pi is used to monitor the system

d. The system soil moisture sensors type of humidity sensor that can detect the intensity of water in the soil (moisture). This sensor is very simple, but is ideal for monitoring water levels in plants 
e. Water sensor functions, Water Level Control is a tool that can facilitate the identification of water levels in a water reservoir. The main function of Water Level Control is to control pump performance

f. Temperature sensors measure the amount of heat or cold energy produced by an object so that it is possible to know or detect the symptoms of temperature changes in the form of Analog and Digital output.

g. The water pump is an element that functions to absorb and encourage water contained in an irrigation system so that it can synthesize and drain water on plants

In the part of making a Digital Irrigation prototype, it can be seen in the architecture that explains the use of sensors used and the process and workings of the system being built.

\section{System Design}

\subsection{Devices design}

The following is a description of the design of the device that will be connected to the client to send and request data about soil moisture using a ground sensor sent to the client server, then the water reservoir and temperature will be connected by the sensor to determine the condition around plants that will be watered and irrigation will be controlled from a smart smartphone installed digital irrigation application. The following is a picture of the design of digital irrigation devices can be seen in picture below.

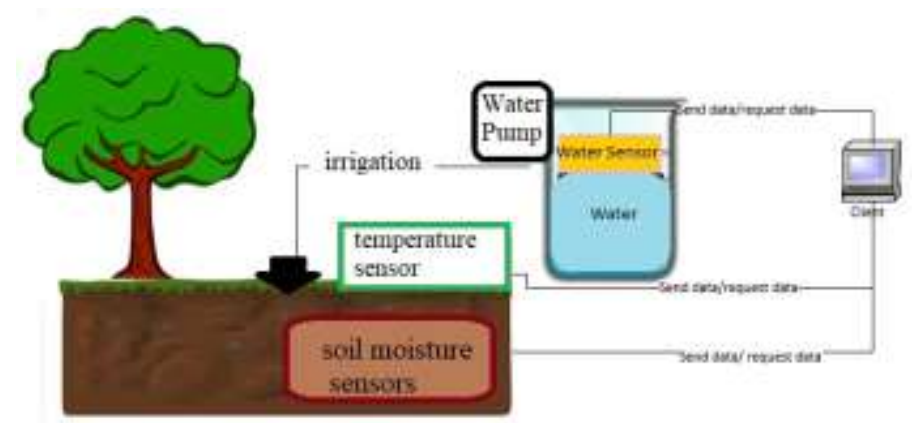

Fig. 1. Devices Design

Microcontroller-based digital irrigation prototype using several sensors to make it easier for users to control plants. In figure two, the irrigation system uses a water pump connected to a water level sensor, if the water in the irrigation is low, the sensor will notify the user to notify that the water in the irrigation is low, and when the water is being collected then if the water is full the sensor will turn off the water pump automatically so that the storage water is not excessive.

On the sensor's soil moisture sensor, it will send a notification when soil moisture is reduced or the water contained in the soil becomes dry, and the irrigation system will automatically be active. That is, the water pump will take water from the reservoir and drain it to the plant, then the water pump will turn on and off according to the humidity conditions of 
the soil sent by the water sensor.The temperature sensor serves to record the temperature around the plant, so that users can find out the temperature at a certain hour, especially when the temperature is dry where plants need water flow as soil moisture.

The recording system of soil moisture data for water requirements and air temperature will be recorded automatically and periodically with sensors connected to Arduino Uno and data sent by sensors will be seen as a list of information on the user's smartphone. In this digital irrigation system all are controlled by the system according to the needs of plants, users can find out what actions should be taken to optimize the water needs of the plants, so that the plants can grow and develop better. all that can be known from the system on the smartphone. Smart phones can send and receive data to microcontroller-based servers and are received by sensors that have been connected using Raspberry and Arduino.

\subsection{System interface design}

The system designed is a necessity from Microcontroller-based digital irrigation. On the user page, the system will be designed using Android to make it easier for users to control and interact with the system.

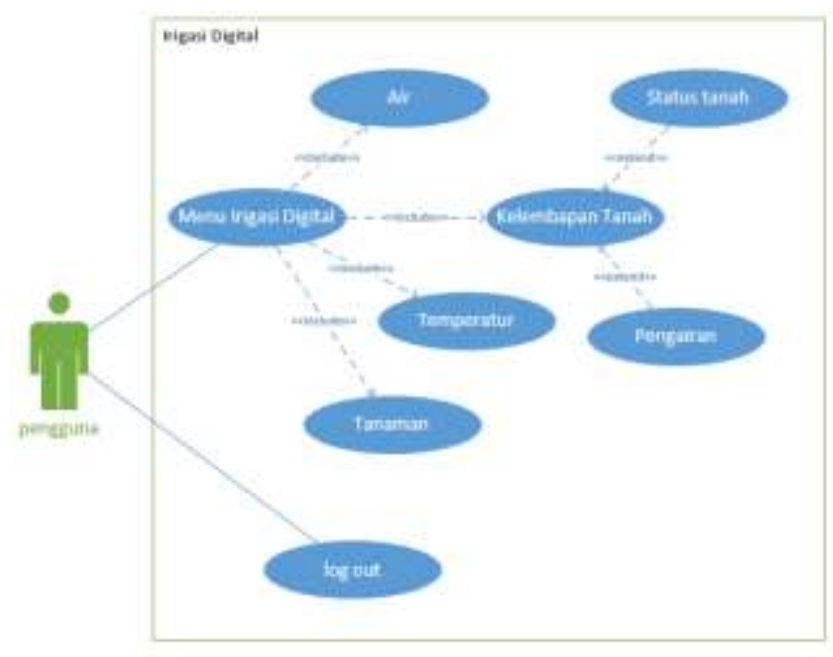

Fig. 2. Use case model

In the menu design there are several options for users to choose the interaction that is done. The following is a description of the system from Figure 3..

a. The water menu allows users to know the list of information on the water menu and the use of water sensors, in this menu users can monitor the amount of water, into water, use water and a digital irrigation system that is set via a smartphone.

b. The menu on soil moisture allows the user to be able to see information about soil conditions and soil moisture, if the signal of the land sent gives information about the land lacking dry water, the system will send a notification that soil moisture is reduced and irrigation can be done automatically. 
c. The temperature menu allows users to find out information about the temperature around the plant. Data will be stored as material for consideration for users to take action on plants.

d. The plant menu users can find out about the information that is in plants, plants have enough water or about the moisture of the soil on the plants. The system will give a warning if the plant is dry. Users can collect data on plants and classify plants based on their type, because the system built for plants allows users to collect data on plants and provide more detailed information about plants using digital irrigation systems controlled by smartphones.

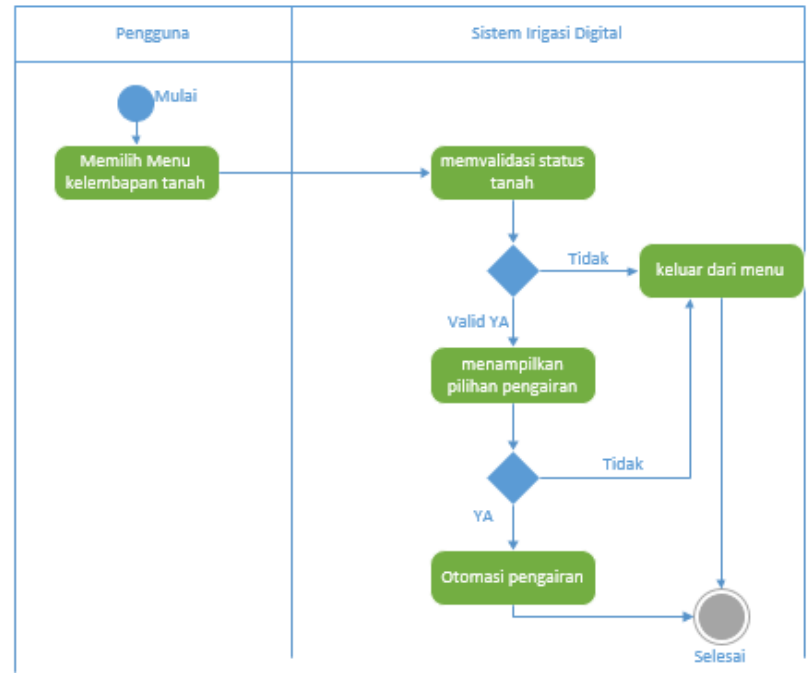

Fig. 3. Activity Soil Moisture

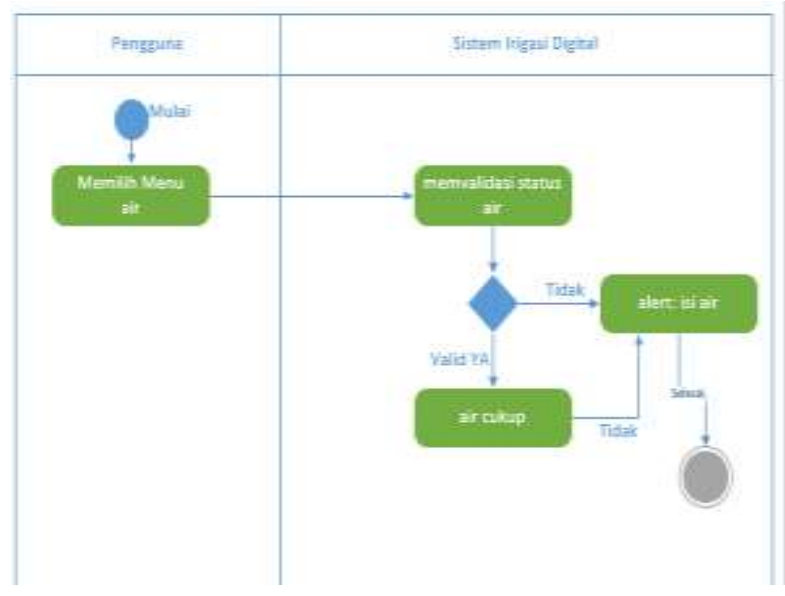

Fig. 4. Activity Water Level 


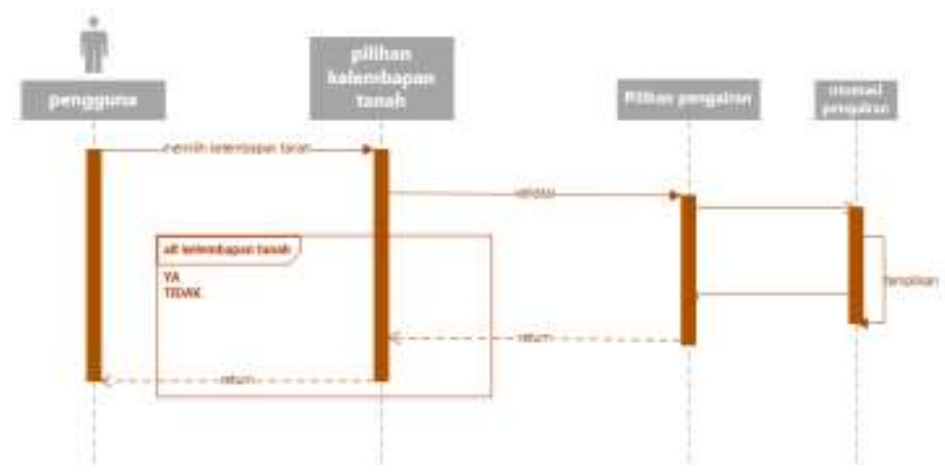

Fig. 5. Sequence Diagram

\section{Result and Discussion}

After the device is finished at the installation, then the next stage of testing and system analysis In this stage the system will be tested and analyzed which will then be made the results of the system test and analysis report.

The device used is a standard mirocontroller device. The microcontroller processing Arduino Uno module (ATMega328P), Ethernet Shield works by providing IP services on Arduino and PC in order to connect to the internet, Raspberry Pi is used to monitor the system. This system uses several sensors, system soil moisture sensors type of humidity sensor that can detect the intensity of water in the soil (moisture).Water sensor functions, Water Level Control is a tool that can facilitate the identification of water levels in a water reservoir. The main function of Water Level Control is to control pump performance, temperature sensors measure the amount of heat or cold energy produced.

The stage of testing and analysis of the system can then be control using recorded data in smartphones that already have data, the data generated is the result of notification sensors that run when the installation is complete.

Visual modeling of digital irrigation systems using UML is a blueprint of the development of microcontroller-based digital irrigation prototypes, Use case diagrams help to understand and use the system being modeled. Use cases explain how actors and use cases interact. class diagram shows the relationship between classes and detailed explanation of each class in the design model. Sequence diagrams explain the interactions of objects arranged in a time sequence. This diagram is specifically associated with use cases, Activity diagrams are also very useful when wanting to describe parallel behavior or explain how behaviors in various use cases interact.

Visual modeling using UML is expected to be a reference for the development of microcontroller-based digital irrigation systems, so that systems that have been designed can continue to be developed so that they become a unified system that can assist in the development of microcontroller-based systems

\section{Conclusion}

Control-based system, can monitor and control water supply systems using smartphones that are connected to the system and can help system users make decisions on their land. All transaction data will be recorded making it easier for users to make decisions. By utilizing 
microcontroller-based Internet of Things (IoT) technology using raspberry Pi and Arduino, where the digital irrigation prototype is run using a smartphone that sends data to microcontroller-based servers and is received by sensors that have been connected using raspberry and Arduino.

This system can be further developed in terms of adding devices such as sensors, or other devices to make it better and easier to use and easy to install by any device, so that it will facilitate agriculture in the future.

\section{Acknowledgment}

I want to convey my deepest appreciation to all those who gave me the possibility to complete this report. A special thank you to the Sari Mulia university for providing practical land and supporting tools in the research, whose contribution to stimulating advice and encouragement, helped me to coordinate my project, especially in writing this report and during the research.

\section{References}

[1] J. Gubbi and R. Buyya. Internet of Things (IoT): A vision, architectural elements, and future directions. Future Generation Computer Systems. vol. 29. no. 7. pp. 1645-1660. (2013).

[2] S. Wolfert, L. Ge, C. Verdouw and M. Bogaardt. Big data in smart farming-a review, Agricultural Systems. Vol. 153. no. 1. pp. 69-80. (2017).

[3] I. Mat, M. R. M. Kassim, A. N. Harun and I. M. Yusoff. Smart Agriculture Using Internet of Things, in 2018 IEEE Conference on Open Systems (ICOS). Langkawi Island, Malaysia. (2018).

[4] P. Jayaraman, A. Yavari, D. Georgakopoulos, A. Morshed and A. Zaslavsky. Internet of things platform for smart farming: Experiences and lessons learnt. IEEE Cloud Computing. vol. 3. (2016).

[5] B. K. Smart Farming: Including Rights Holders for Responsible Agricultural Innovation. Technology Innovation Management Review. vol. 8. no. 2. pp. 7-14. (2018).

[6] G. R. J. E. C. F. J. Y. \&. S.-R. G. Soto-Romero. A new bi-frequency soil smart sensing moisture and salinity for connected sustainable agriculture. Journal of Sensor Technology. no.2. p. 01925585. (2019).

[7] S. F. Barrett. Arduino microcontroller processing for everyone!". Synthesis Lectures on Digital Circuits and Systems. vol. 8. no. 4. pp. 1-513. (2013).

[8] D. Miorandi and S. Sicari. Internet of things: Vision, applications and research challenges. Ad Hoc Networks. vol. 10. no. 7. pp. 1497-1516. (2012)

[9] L. Atzoria, A. Iera and G. Morabito. The Internet of Things: A survey. Computer Networks. vol. 54. no. 15. pp. 2787-2805. (2010).

[10] J. Chen and Z. Tian, Trust architecture and reputation evaluation for internet of things. Journal of Ambient Intelligence and Humanized Computing. vol. 10. no. 55. (2018).

[11] M. Saeid, M. Jadab and M. Reza. Machine learning for internet of things data analysis: a survey, Digital Communications and Networks. vol. 4. no. 3. pp. 161-175. (2018). 